\title{
Francisco de Quevedo, alias «Diablo Cojuelo». Pasajes, hechos e hipótesis de alusiones en la novela de Vélez de Guevara con la figura de Quevedo al fondo
}

\author{
Ramón Valdés Gázquez \\ Departament de Filologia Espanyola \\ Facultat de Lletres \\ Universitat Autònoma de Barcelona \\ 08193 Bellaterra (Barcelona) \\ ramonvaldesg@hotmail.com \\ [La Perinola, (Issn: 1138-6363), 22, 2018, pp. 347-373] \\ DOI: $10.15581 / 017.22 .347-373$ \\ A Daniel Fernández y Santiago Restrepo, \\ antiguos alumnos como muchos los desearían
}

En este artículo es nuestro deseo exponer algunos puntos y aspectos que hasta ahora no se han destacado o no han tenido suficiente eco y nos parecen llamativos en torno a la figura y la obra de El diablo Cojuelo en relación con Francisco de Quevedo y con su obra ${ }^{1}$.

Algunos paralelismos entre pasajes de la obra de Luis Vélez de Guevara y diferentes obras quevedescas son obvios y ya han sido señalados. Pero hay otros aspectos y puntos de relación entre el madrileño y su obra y la novela del ecijano que resultan muy llamativos y que, aunque hayan sido vistos, no han sido suficientemente atendidos, por lo que tal vez convendría volver sobre ellos, reconsiderarlos, ofrecer más datos y ordenarlos a la luz de las últimas investigaciones. Podemos partir de los hechos de que al «poeta de cuatro ojos» se le conociera también como “Patacoja» o cel diablo Cojuelo» y de que el diablillo inicialmente esté preso, como cuando se compuso y publicó la novela lo estaba Quevedo, para continuar con el desarrollo crítico y burlesco por parte del «Diablo Cojuelo» de todo un relato satírico de corte muy quevedesco, la posible alusión en algún punto a las legendarias aventuras del autor madrileño en Italia, la imitación de algún pasaje significativo, así como, en fin, la circunstancia, que parece de todo menos casual, de que el editor y los censores que aprobaron el Cojuelo fueran los mismos

1. Debo agradecer muy sinceramente las observaciones de los evaluadores que, espero, han servido para mejorar el presente artículo. 
que una década antes habían atacado, con idénticos argumentos, los Sueños y discursos y el Discurso de todos los diablos, obras que, sin duda y paradójicamente, fueron fuente de inspiración ineludible para Vélez.

En el abordaje de todos los temas que hemos adelantado en el párrafo anterior nos encontraremos con diversas acepciones y concreciones en torno al término y concepto de figura tal como este ha sido definido y analizado por Eugenio Asensio, Maxime Chevalier, Ignacio Arellano o Melchora Romanos. Desde el uso retórico de la figura compuesta o grotesca a través de la técnica del apodo, que encarna el propio Cojuelo, hasta el concepto de figura folclórica en el que el Diablo Cojuelo es una especie de prefiguración -salvo el guante a la reiteración- de lo que con el tiempo se convertiría en la figura folclórica del propio Francisco de Quevedo. Por otro lado, la composición de esa figura se corresponde, también, con la que el propio Quevedo fomenta a través de autorretratos y autopromoción en sus obras satíricas y burlescas de juventud. Se proyecta y propicia así, en cierto modo, a través de su figura literaria y máscara satírica, su propia conversión en figura o, incluso, figura folclórica; algo que, sin duda, visto lo que pasó con el tiempo, consiguió. Tanto, que, hasta su propia sombra, cual Peter Pan, se le escapó de las manos desde fechas muy tempranas y huyó de sus propios pies haciéndose cada vez más grande y más larga, hasta alcanzar las fechas de su prisión y su muerte, y más allá. La publicación de El diablo Cojuelo tal vez fue un testimonio más de ello.

El arte del Motejar y EL apodo EN LAS figuras Compuestas de Quevedo y VéLez

La primera percepción que tenemos del diablo Cojuelo en la novela de Luis Vélez, a través de los sentidos de don Cleofás, personaje al que va siguiendo además de la justicia el narrador, es un suspiro. Cleofás no ve nada y no sabe quién más hay ni dónde está en la buhardilla del astrólogo. Al oír por segunda vez un misterioso suspiro que no entiende de dónde procede ni quién lo emite, entre asustado y valiente, exige que se declare: «QQuién diablos suspira aquí?». No sabe todavía qué oportuna resulta su pregunta, porque efectivamente una voz le responde desde una redoma que ahí lo «tiene preso ese astrólogo que vive ahí abajo, porque también tiene su punta de la mágica negra y es mi alcaide dos años habrá». Cuando el estudiante deduce «Luego ¿̈familiar eres?», refiriéndose a que es un demonio familiar, auxiliar del astrólogo, no pierde su interlocutor la ocasión de hacer un malicioso chiste, sobre la base de un equívoco:

Harto me holgara yo - respondieron de la redoma- que entrara uno ['un familiar, aquí la dilogía en zeugma] de la Santa Inquisición para que, metiéndole a él en otra de cal y canto, me sacara a mí desta jaula de papagayos de piedra azufre. 
Tal vez, con la alusión a la «jaula de papagayos de piedra azufre» tengamos un primer elemento icónico (términos probablemente referidos al color y olor de la redoma), pero notemos que hasta aquí, Luis Vélez nos está hurtando -y lo seguirá haciendo por unas líneas- cualquier referencia visual. Se entabla entonces el rápido diálogo entre el estudiante y el "vidro endemoniado», en que le pregunta si es diablo famoso, Lucifer, Satanás, Belcebú, Barrabás, etc. Al final se confiesa «demonio más por menudo", pero también orgulloso de haber traído al mundo «la zarabanda, el déligo, la chacona...», «los títeres, los volatines». Hasta que dice «Y al fin, yo me llamo el diablo Cojuelo». Deshecho este primer misterio, la descripción física no llega todavía. El demonio explica el porqué de su nombre al estudiante $\mathrm{y}$, tras conminarlo a romper la redoma y liberarlo, ofreciéndole a cambio «muchos gustos», don Cleofás coge un cuadrante del astrólogo y con un golpe - por fin llegamos a la descripción visual- hace

gigote del vaso, inundando la mesa sobredicha de un licor turbio, escabeche en que se conservaba el tal diablillo; y volviendo los ojos al suelo, vio en él un hombrecillo de pequeña estatura, afirmado en dos muletas, sembrado de chichones mayores de marca, calabacino de testa y badea de cogote, chato de narices, la boca formidable y apuntalada en dos colmillos solos -que no tenían más muela ni diente los desiertos de las encías-, erizados los bigotes como si hubiera barbado en Hircania, los pelos de su nacimiento ralos, unos aquí y otros allí, a fuer de los espárragos, legumbre tan enemiga de la compañía que si no es para venderlos en manojos no se junta; bien hayan los berros, que nacen unos entrepernados con otros, como vecindades de la corte (perdone la malicia la comparación).

Asco le dio a don Cleofás la figura, aunque necesitaba de su favor para salir del desván...2

Ignacio Arellano anotaba que aquí figura se utiliza “con el sentido satírico de "hombre ridículo, feo, de mala traza" [Diccionario de Autoridades]» remitiendo a los clásicos estudios de Eugenio Asensio y Melchora Romanos, además de a la Vida de corte de Quevedo ${ }^{3}$. Según las consideraciones en la Vida de corte efectivamente entraría el diablo Cojuelo entre las figuras naturales, que son «los enanos, agigantados, contrahechos, calvos, corcovados, zambos y otros que tienen defectos corporales» ${ }^{4}$, aunque estos, se advierte, no son merecedores de crítica si no es que utilizan tales defectos para vivir y mantenerse de ellos. Hay otras muchas figuras en la Vida de corte que merecen el apelativo por su deformidad moral, su vanidad y superficialidad, su hipocresía y comportamiento: son las figuras artificiales. De esas figuras se ocupa Quevedo en

2. Vélez de Guevara, El diablo Cojuelo, ed. Valdés, p. 18; las diversas citas que se han ido realizando hasta aquí, todas del tranco I, pp. 14-18.

3. Vélez de Guevara, El diablo Cojuelo, ed. Arellano y Fernández, p. 76 n. Véase Asensio, 1965, y Romanos, 1982. Añádase sin falta di Pinto, 2007 y Rodríguez Cuadros, 2007.

4. Quevedo, Vida de corte, p. 322. 
la Vida de corte, sí, pero también en muchas de sus otras obras satíricas y narrativas, como por ejemplo El mundo por de dentro, cuyo planteamiento, en el que el Desengaño juega un papel de guía ante el cándido narrador similar al desempeñado por el Cojuelo con Cleofás, recuerda mucho al inicio del tranco III de El diablo Cojuelo ${ }^{5}$. A poco que lo pensemos, las figuras a las que se aludía con este nombre e intención en el Siglo de Oro, en tanto que feas y ridículas por diferentes cuestiones tanto físicas como morales o sociales, no son sino tipos cómicos o satíricos, en parte tradicionales y folclóricos, en parte exponentes de los nuevos vicios o comportamientos de la sociedad. Pero más allá de la diversidad de los tipos que constituyen las figuras, lo que nos interesa ahora es la técnica utilizada en su retrato cuando el autor - sea Quevedo, sea Vélez- se detiene más en ellas para desarrollarlas y darles mayor rango satírico. Las técnicas utilizadas por Quevedo, que son las mismas que siguió Vélez en su retrato recién citado del Cojuelo, tienen mucho que ver con las de la caricatura satírica, el motejar por apodos, que estudió Maxime Chevalier, o también lo que Margarita Levisi llamó «figuras compuestas» sobre la base de los imaginativos retratos de Arcimboldo.

Según recordaba Maxime Chevalier (1992, p. 134), ya en la literatura del siglo xvi abunda la técnica del apodo, desarrollándose luego hasta alcanzar la caricatura (retrato 'recargado' por acumulación). Esos apodos o conceptos en el sentido que le da Gracián eran a la vez demostración del ingenio del autor y elementos caracterizadores en la composición de ese retrato, con frecuencia satírico, que puede alcanzar a aspectos tanto físicos, es el caso del Cojuelo, como físicos y morales que podemos observar en el maestro de la caricatura, Quevedo. En esta tradición, encontramos la posibilidad de acumular distintos apodos para incidir sobre una misma característica o rasgo (la pequeñez, por ejemplo: Chevalier, 1992 , p. 67), o, por alusión a distintos rasgos, como ahora nos interesa, componer un retrato complejo. Las metáforas que elige Luis Vélez, los símiles, los usos traslaticios, los diminutivos y las hipérboles presentan una figura ridícula y despreciable en su aspecto físico (otros aspectos los ha abordado Vélez en líneas anteriores). El diablo es descrito en esta

5. Compárese: «Yo soy el Desengaño [...] Si tú quieres, hijo, ver el mundo, ven conmigo, que yo te llevaré a la calle mayor, que es a donde salen todas las figuras, y allí verás juntos los que por aquí van divididos sin cansarte; yo te enseñaré el mundo como es, que tú no alcanzas a ver sino lo que parece. -¿Y cómo se llama -dije yo- la calle mayor del mundo, donde hemos de ir? -Llámase -respondió- Hipocresía, calle que empieza con el mundo y se acabará con él» (Quevedo, Mundo por de dentro, Sueños y discursos, pp. 361-362); el Cojuelo inicia su tranco III dedicando atención a lo que Quevedo llamaría en la Vida de corte (figuras artificiales»: «don Cleofás iba siguiendo a su camarada, que le había metido por una calle algo angosta, llena de espejos por una parte y por otra, donde estaban muchas damas y lindos mirándose y poniéndose de diferentes posturas de bocas, guedejas, semblantes, ojos, bigotes, brazos y manos, haciéndose cocos a ellos mismos. Preguntole don Cleofás qué calle era aquella, que le parecía que no la había visto en Madrid, y respondiole el Cojuelo: -Esta se llama la calle de los Gestos, que solamente salen a ella estas figuras de la baraja de la corte, que vienen aquí a tomar el gesto con que han de andar aquel día y salen con perlesía de lindeza» (Vélez, El diablo Cojuelo, p. 33). 
acumulación de rasgos como un ser deforme con rasgos de un animal, incluso de un alimento, de una cosa, una realidad baja e indigna.

Evangelina Rodríguez Cuadros se ha planteado cómo en la concepción de estas figuras se pudieron producir trasvases entre literatura y pintura, y menciona como uno de los puntos de referencia las “teste grottesche» o monstruosas de Leonardo da Vinci. Efectivamente, el Cojuelo se nos presenta «sembrado de chichones mayores de marca), chato, boca formidable y desdentada, con cuatro pelos ralos: un compendio de deformitas y feísmo que tiene mucho que ver con esas cabezas monstruosas que dibujó da Vinci. Las alusiones a las distintas frutas y verduras (calabacino, badea, espárragos, berros), nos podrían recordar asimismo, claro, las composiciones de Arcimboldo, aunque al bagaje de esta imaginería grotesca contribuyen también la literatura clásica, humanística y algún autor casi contemporáneo, como Rabelais (del cual derivan, a su vez, otra serie de grabados, Les songes drolatiques) ${ }^{6}$.

En fin, en el retrato del Cojuelo se van mezclando en una especie de inventario heteróclito desde elementos descriptivos puramente referenciales (pequeña estatura, muletas, chato de narices, boca formidable), con símiles y metáforas, apodos, que implican alusión a vegetales, pero también a animales (barbado en Hircania) y alimentos elaborados, pues el diablillo se ha conservado en el interior de la redoma hasta entonces en un escabeche ${ }^{7}$. Son elementos disparatados e inesperados cuya misma mezcla y aparición causa sorpresa. Como la causa ese último apodo en el remate final en que, por asociación con el resto de verduras aludidas, pero sin servir ya para el retrato del personaje, se menciona en el último momento a «los berros que nacen unos entrepernados con otros, como vecindades de la corte»; retoma aquí Vélez una tradición que se remonta, según Chevalier (1992, pp. 36-37), a tiempos de los Reyes Católicos, pues desde entonces se conservan testimonios de la costumbre de apodar edificios, jardines e incluso pueblos.

Sin embargo, claro está, aparte de estos apodos ingeniosos y conceptuosos de ciudades o pueblos, existía también la costumbre más extendida de apodar a personas, y en ella se inscribe la caricatura del diablo Cojuelo. Y por supuesto, las que le precedieron y más probablemente influyeron son las que realizó Quevedo en su prosa, y vienen en seguida a la mente, tantas veces aducidas y analizadas: las del dómine Cabra, en el Buscón, el licenciado Calabrés, en El alguacil endemoniado o la dueña

6. Véase Arellano, 2003, pp. 254-273, con los modelos (satíricos latinos, Erasmo, Arcimboldo, Teofrasto, etc.) y bibliografia allí señalados (Spitzer, Asensio, Schwartz, Rico, etc.).

7. Recuérdese que la utilización de imágenes cibales es un recurso degradante fundamental en el lenguaje satírico del Cojuelo, de Quevedo y del siglo xviı, según destacó con mucho acierto desde sus primeras ediciones de esta novela Enrique Rodríguez Cepeda con Enrique Rull, 1968, pp. 80-81. Basta recordar ese inicio del tranco III con la alusión al "puchero humano de la corte» donde empiezan "a hervir hombres y mujeres, unos hacia arriba y otros hacia abajo y otros de través» (p. 33). 
Quintañona y don Diego de Noche en el Sueño de la Muerte. Hay que contar que, además de las caricaturas por apodos mencionadas, también el pasaje de Enrique de Villena en el Sueño de la muerte sin duda influyó en Vélez para su retrato y concepción del Cojuelo. Conservado en una grandísima redoma como (un gigote», bulle «en un ardor terrible» y tras juntarse «unos pedazos de carne y unas tajadas [...] al fin se coció y enderezó un hombre entero [...] nacido en guisado» con el que dialoga el personaje de Quevedo ${ }^{9}$.

Después de unas pocas líneas la parte más ingeniosa, divertida e importante del retrato de Diego de Noche es una serie de apodos que inciden en su condición de parásito social, gorrón de comidas en mesas ajenas:

-Más precio haberte visto - dije yo- que a cuanto tengo. iOh, estómago aventurero! iOh, gaznate de rapiña! iOh, panza al trote! iOh, susto de los banquetes! iOh, mosca de los platos! iOh, sacabocados de los señores! iOh, tarasca de los convites y cáncer de las ollas! iOh, sabañón de las cenas! iOh, sarna de los almuerzos! iOh, sarpullido del medio día! No hay otra cosa en el mundo sino confrades, discípulos y hijos tuyos ${ }^{10}$.

En este caso, los apodos, dirigidos en vocativo al propio Diego de Noche por su interlocutor, el personaje de Francisco de Quevedo, responden a la vez al arte de motejar y apodar de los siglos de Oro, pero también a la acepción más extendida que conservan todavía las palabras apodo, mote de alias o sobrenombre, que se pueden centrar en una cualidad de la persona y pasar a denominarla así en lugar de por su nombre ${ }^{11}$. En la medida en que esa cualidad puede ser negativa, el apodo puede ser malicioso, pero sin renunciar al ingenio. Es lo que ocurre con los apodos que dedica Quevedo a don Diego de Noche: en este caso parte de la gracia está en la panoplia de apodos que es capaz de inventar.

Después de este repaso de la relación que se puede observar en la presentación de la figura del diablo Cojuelo con las técnicas utilizadas por Quevedo, llegamos ya a otra de las cuestiones que queríamos abordar en este artículo, y ahora no se trata ya tanto de estrictas relaciones literarias entre las obras, sino también de hacer notar que el propio Quevedo recibió el sobrenombre de «Diablo Cojuelo». Más tarde ofreceremos los testimonios de uso del apodo, pero las razones están claras, pues los nexos básicos entre el apodo y Francisco de Quevedo son varios: el literato como personaje con vínculos con el diablo (por aficiones personales -en seguida lo veremos- y por sus sátiras), y la propia

8. Quevedo, Buscón (pp. 557-559) y Sueños y discursos (pp. 249-252: licenciado Calabrés; pp. 439-440: dueña Quintañona, y 445-447: Diego de Noche).

9. Quevedo, Sueños y discursos, p. 418.

10. Quevedo, Sueños y discursos, pp. 446-447.

11. Puede consultarse al respecto el Diccionario de la Real Academia de la Lengua Española, bajo ambas voces. 
cojera como rasgo conocido y caracterizador del personaje histórico. Es difícil determinar si el apodo, que con frecuencia se aplica con intención maliciosa, satírica o burlesca, podía resultar ofensivo o no para el designado. La alusión a la cojera, desde luego, parecería caer fuera de las normas de urbanidad o cortesía del motejar en la época, pues alude a una minusvalía ${ }^{12}$. Lo dice Quevedo, aunque sigue en esto a tratadistas de urbanidad y cortesía de la época: al tratar en su Vida de corte de las figuras naturales y aclarar que son los que «tienen defectos corporales», dice que sería (inhumanidad y mal uso de razón» censurarlos o denigrarlos sobre esa base (Vida de corte, p. 322). Sin embargo, queda sobradamente atestiguado en las colecciones de apotegmas y la literatura satírica que tanto cortesanos como truhanes, escuderos como eruditos escritores satirizaban y apodaban con mayor o menor ingenio utilizando esos defectos; Quevedo, el primero y más cruel. Por otro lado, aunque se podría considerar que, en tanto que por la alusión a la cojera se trataba de un "mote descubierto» (es decir, carente de ingenio y mérito aparte de falto de urbanidad), lo cierto es que no dejaba de tener cierta gracia. Como decíamos antes, los nexos entre el apodo designador y el sujeto designado son varios. No solo por cojo, sino también por «diablo» (lo veremos en seguida), se puede asociar a Quevedo con el diablo Cojuelo. Y, por otro lado, esa figura folclórica preexistente no dejaba de presentar ciertos rasgos de simpatía que denotaban el propio diminutivo hipocorístico, afectivo: Cojuelo $^{13}$. En fin, el apodo, aunque aluda a lo que se considera un (defecto de figura natural», resulta ingenioso.

\section{Quevedo, “hacia diablo Cojuelo» ${ }^{\mathrm{I}}$, entre la autorrepresentación Y LA CONSTRUCCIÓN DE UNA FIGURA FOLCLÓRICA}

En sus inicios literarios y hasta fechas no demasiado seguras, Quevedo se explayó difundiendo de sí mismo una imagen de crápula, vicioso, endemoniado incluso; enfant terrible, irreverente, épatant. Recordemos que en la presentación que pone al frente del Memorial que dio en una academia pidiendo una plaza y indulgencias que le mandaron escribir (en el ínterin que vacan mayores cargos) concedidas a los devotos de monjas, de fecha temprana (1600-1605), aludía a sí mismo como “cofrade de la Carcajada y Risa» y -subrayaremos las expresiones que implican un retrato moral negativo en que el autor se complace- hombre «nacido para mal», «de muchas fuerzas y de otras tantas flaquezas», con

12. Véase Chevalier, 1992, capítulos II-IV y, específicamente, pp. 39, 43, 57-59 y 6465. Véase también Alonso Asenjo, 2007.

13. Véase el prólogo de Valdés, 1999, pp. LX-LXvi, en su edición de El diablo Cojuelo, así como los magníficos repasos de Pedrosa, 2001 y 2004, y Delpech, 2004 y 2006.

14. Aclaremos, para evitar confusiones, que en ningún lugar aparece la expresión entrecomillada, que es calco sobre la expresión "hacia caballero» que utilizara en algún momento Quevedo. Lo que nos interesa destacar y queremos expresar con esta broma es cómo Quevedo mismo, en su autorrepresentación, probablemente propició que en algún momento se le aplicara el apodo de «diablo Cojuelo». 
"muy grandes cargos de conciencia», «ordenado de corona, pero no de vida», "dado al diablo, prestado al mundo y encomendado a la carne; rasgado de ojos y de conciencia», y (señalado de la mano de Dios» ${ }^{15}$. Aunque este escrito podría estar condicionado por ser para academias, pues según reza el título fue compuesto para solicitar plaza en una de ellas, y en este sentido el autorretrato es burlesco y autovejatorio, en otros escritos tempranos suyos Quevedo insistirá en esos mismos rasgos en su autorrepresentación. Le interesaba promocionar y labrarse una imagen de joven ingenio satírico y burlesco para descollar en la corte, "arquetipo literario de la ingeniosidad burlesca, proceso en que las academias debieron de jugar un papel sustancial» ${ }^{16}$. Esa máscara satírica y burlesca en que coincidían autor, narrador y personaje, es la misma que va a protagonizar y narrar todos y cada uno de los Sueños y discursos, especialmente los primeros, y la que va a presentarlos en los distintos prólogos, incidiendo en los mismos rasgos de autocaracterización.

En la dedicatoria de El alguacil endemoniado al conde de Lemos, presupone jactanciosamente: «Bien sé que a los ojos de V. Señoría es más endemoniado el autor que el sujeto» ${ }^{17}$. Y de nuevo, comienza la dedicatoria al duque de Osuna de El mundo por de dentro, con sarcasmo irreverente y sacrílego: «Estas son mis obras: claro está que juzgará vuestra Excelencia que siendo tales no me han de llevar al cielo; mas como yo no pretenda dellas más de que en este mundo me den nombre... ${ }^{18}$. En 1616 tenemos testimonio de cómo el Quevedo cortesano sigue ejerciendo de bufón diabólico; en su correspondencia, con fragmentos satíricos y jocosos, con el duque de Osuna, se despide en una ocasión con una autorreferencia coincidente con las de su prosa burlesca: «Yo quedo dado al diablo, y aun dado no me quiere, y rabio por irme de aquí, porque está tan mal lugar que aun el diablo no se precia de su oficio» ${ }^{19}$. Esta imagen acaba forjándose con tal fuerza que va a ir mucho más allá de estas obras y estos tiempos, por mucho que, por su aspecto frívolo, Quevedo se arrepintiera en algún momento, sin poder ya zafarse de ella ${ }^{20}$.

15. Quevedo, Memorial que dio en una academia, pp. 173-174; para la datación de este opúsculo, Azaustre, 2007, p. 152. Hemos incluido la expresión «señalado de la mano de Dios» porque, aunque normalmente aludiría a la cojera (a la que efectivamente hace referencia en este autorretrato en más de una ocasión), a través de esta expresión, precisamente, se evoca la creencia de que los señalados por Dios con defectos físicos lo son, precisamente, como una manera de evidenciar sus defectos morales (véase Beccaria, 1995, 126 y Valdés, 1999, p. LXIII).

16. Véase Gutiérrez, 2005a, pp. 188 y ss. Véase también Vélez-Sainz, 2005.

17. Quevedo, Sueños y discursos, p. 145.

18. Quevedo, Sueños y discursos, p. 357.

19. La cita corresponde a una carta remitida al duque de Osuna en abril de 1616 , reproducida en Ettinghausen, 2011, p. 11. La carta siguiente, remitida en la misma fecha, llevaba un título que decía «El diablo anda suelto».

20. Los intentos de Quevedo de dominar, amortiguar o neutralizar los efectos de esa imagen entre frívola e irreverente se podrían situar en torno a 1630, tal vez tras la publicación del Novus Index de 1632, según Gutiérrez, 2005b; no obstante, también se puede 
Sin duda, ese Quevedo que va estableciendo unos fuertes vínculos entre autor, personaje y narrador satírico en primera persona de los Sueños y discursos, sigue labrándose la imagen de sí mismo que comenzó con los autorretratos del Memorial que dio en una academia o de la Carta a la rectora del Colegio de las Vírgenes; está construyendo, en fin, un personaje literario llamado Francisco de Quevedo que, tras haber observado el Juicio final, haber charlado jocosa y placenteramente con demonios, visitar el infierno y cruzarse con personajes históricos y literarios, cuando llega al Sueño de la muerte pelea incluso con Diego Moreno por las infamias que le ha levantado en un entremés, poniéndose a su altura, a la altura de sus entes de ficción y de los personajes folclóricos.

Todo coadyuvó para que Francisco de Quevedo -y él, el primero- se constituyera en figura folclórica e incluso proverbial. Todavía hoy se pueden recoger chistes y facecias tradicionales de Francisco de Quevedo, del que se recuerda proverbial y antonomásticamente su aspecto burlón, mordaz, ingenioso y también, en no pocas ocasiones, su gusto por lo escatológico. José Manuel Pedrosa (2003, donde prometía una monografía que esperamos) y María del Mar Jiménez Montalvo (2011) recogen en sendos preciosos artículos facecias y chascarrillos protagonizados por Quevedo que se han podido recolectar desde Navarra a La Mancha o Extremadura, de Brasil a Venezuela o incluso entre hispanohablantes isleños de Louisiana.

En fin, la enorme fama de Quevedo, su cojera como un rasgo real y tópico en su retrato, su preeminencia como autor en el terreno satírico, su ingenio y su mordacidad, además de su fuerza y potencia como personaje literario, su predilección por demonios e infiernos en la ficción satírica propició lo que vamos a ver inmediatamente: que se le asimilara, a través del apodo, a otro personaje folclórico y proverbial, otro trick$s^{2}{ }^{21}$, ya plenamente vigente como tal en sus días, el diablo Cojuelo.

Francisco de Quevedo, apodado en invectivas como «el diablo Cojuelo»

No nos consta, aunque se nos puede escapar, que Francisco de Quevedo aludiera en sus autorretratos a sí mismo como «Diablo Cojuelo», a pesar de haberlo hecho en tanto que cojo o «dado al diablo».

percibir una crisis o un giro a partir de fechas bastante más tempranas: José Manuel Blecua habló de una «tremenda crisis» de don Francisco en 1613, tal como recuerda Pablo Jauralde Pou, 1998, p. 291; véase también Ettinghausen, 1982, pp. 38-39, y Valdés, 2016, p. 241. Es posible que Quevedo se debatiera entre su propia imagen de autor mordaz y bufonesco frente al devoto y serio en más de una ocasión en su vida. Es cierto, no obstante, que él identificó los años y obras de juventud como los que le proporcionaron fama de mordaz satírico; resulta muy interesante en este sentido el romance «Enigma del ojo de atrás» y el análisis que propone Gutiérrez, 2005b.

21. Sobre el concepto de trickster como espíritu burlón y su relación con la figura folclórica del Cojuelo, e incluso con la de Quevedo, véase Delpech, 2004, pp. 125-130, y Pedrosa, 2008, p. 109. 
De hecho, el diablo Cojuelo, a pesar de su importancia como figura folclórica, no aparece, si no se nos ha escapado alguna alusión, siquiera en los Sueños y discursos o en el Discurso de todos los diablos. Sí lo menciona Quevedo en la Perinola al doctor Juan Pérez de Montalbán, a propósito de Polifemo como figura - en el sentido alegórico ahora- del diablo: «En el auto del Polifemo hay una novedad: que hasta ahora había diablo cojuelo solamente, y ahora hay diablo tuerto con un solo ojo, porque Polifemo es el diablo »22. Tal vez esta simple alusión fue la que desencadenó que, en un par de escritos de reacción a la Perinola y contra Quevedo escritos por sus enemigos, se aludiera a él ya con el apodo de «diablo Cojuelo», como muy bien subrayaron Rodríguez Cepeda y Vivar ${ }^{23}$.

Con anterioridad, Cristóbal Suárez de Figueroa lo había apodado en El pasajero con el neologismo jocoso: «antojicojo»: “Desean autorizarse los a quien cierto antojicojo llamó "caballeros chanflones", con afirmar de sí muchas cosas» ${ }^{24}$. Pero es tras la polémica generada por la Perinola cuando vemos el primer apodo público a Quevedo del que tenemos constancia como «diablo Cojuelo». El blanco del furibundo ataque de la Perinola había sido la miscelánea Para todos de Juan Pérez de Montalbán, publicada en la primavera de 1632. Quevedo, según ha deducido Fernando Plata por otros testimonios ${ }^{25}$, debió de escribir su opúsculo rápidamente después, entre abril y julio del mismo año y lanzarlo a circular anónimo y manuscrito. Y se desencadenó entonces una polémica en la que uno de los hitos fue la respuesta que el propio Juan Pérez de Montalbán habría de escribir, y que tituló Trompa del doctor Juan Pérez de Montalbán contra La Perinola de don Francisco de Quevedo, diablo Cojuelo, jorobado y con cuatro ojos. Más allá del título, en el texto insiste en aludir a su destinatario como «diablo cojo, corcovado y con cuatro ojos» ${ }^{26}$ y más adelante, en vocativo, como “cojo infernal», advirtiéndole que su alma "está amenazando ruina», sin dejar de referirse asimismo a sus Sueños y a que entró en los infiernos para añadir cerca del final:

Claro está, bravo pataratero por autor, un día de éstos ha de hacer santo a un diablo cojuelo, por ser su verdadera efigie. A este hombre, por ley inviolable, lo había de castigar la Inquisición, porque de lo bueno dice mal, y de lo malo, dice bien, yendo siempre contra las costumbres, por donde merece ser destruido ${ }^{27}$.

Las bases del apodo solo son, en nuestra opinión, la cojera y las querencias infernales de Quevedo, pero poco más. Es decir, por el momen-

22. Quevedo, Prosa festiva completa, ed. García Valdés, pp. 498-499.

23. Rodríguez Cepeda y Vivar, 1998.

24. Suárez de Figueroa, El pasajero, p. 569.

25. Plata, 2006, p. 248.

26. Pérez de Montalbán, Trompa, p. 943.

27. Pérez de Montalbán, Trompa, p. 944, 947 y 948. El apodo en el título de la obra de Pérez de Montalbán fue ya subrayado por Rodríguez Cepeda y Vivar, 1998, p. 174, que también estudiaron el contexto de la polémica. 
to no se produce una asimilación entre la figura folclórica del Cojuelo y el personaje literario de Quevedo a través de sus rasgos comunes, más allá de lo dicho y quedándose casi en la pura nominación. No recoge ni evoca Pérez de Montalbán ingenio, rebeldía o simpática travesura. Lógico en el tono enconado de su Trompa, de la que, por cierto, no se sabe la fecha precisa de redacción. La intención y la lógica de ofensarespuesta (Perinola / Trompa) parecería apuntar a una reacción y composición tempranas, incluso en el propio 1632, pero algunos pasajes parecerían invitar a retrasarla hasta $1636-1638^{28}$.

De estas mismas fechas, con datación declarada en su editio princeps de 1635, es El tribunal de la justa venganza, donde se atacan sistemáticamente diversas obras de Quevedo achacándolas de muestras de mal gusto impías y sacrílegas. Los nombres que se han aducido para la autoría o co-autoría son los de Luis Pacheco de Narváez, fray Diego Niseno y, en último término, el de Juan Pérez de Montalbán (evitaremos aquí entrar en discusiones sobre la autoría $)^{29}$. Sea como sea, el autor o los autores de la obra sin duda eran enemigos de Quevedo. Tiene interés consignar que María José Alonso ha localizado un nuevo manuscrito, tal vez anterior al impreso, y ha cuestionado la veracidad de los datos de impresión. Duda que se compusiera en Valencia en los talleres de los pretendidos «herederos de Felipe Mey» y subraya en cambio los parecidos de composición tipográfica de la portada con otro libro publicado en Madrid en 1636: curiosamente, La fama póstuma de Lope de Vega, de Pérez de Montalbán, que fue costeada por su padre, Alonso Pérez, y realizada en los talleres de la Imprenta del Reino, datos que resultarán relevantes también para nosotros ${ }^{30}$.

El título completo de la obra, en cierto modo, retomaba los autorretratos y escritos burlescos del propio Quevedo. Dice así: El tribunal de la justa venganza erigido contra los escritos de D. Francisco de Quevedo, maestro de Errores, doctor en Desvergüenzas, licenciado en Bufonerías, bachiller en Suciedades, catedrático de Vicios y proto-Diablo entre los hombres. Desde la portada, pues, Quevedo apodado como proto-Diablo. En el cargo 18 de la segunda audiencia del Tribunal (la obra sigue la estructura de un procesamiento judicial), hablando del Buscón, se dice de Quevedo que

28. El codex unicus que conserva la Trompa es una copia manuscrita fechada en 1688 , de modo que es posible que contenga interpolaciones o amplificaciones ajenas a la mano de Montalbán. Con todo, el texto, tal como nos llega, incluye una mención al Memorial a Luis XIII (que lleva dedicatoria de julio de 1635) y una alusión a Lope de Vega que parece posterior a su muerte a finales de agosto de 1635 («me quise arrimar al Fénix de los ingenios Lope de Vega Carpio, confesándole por mi maestro y por fuente clarísima, como lo ha explicado su fama con las obras que hizom, Trompa, p. 944). Aunque la datación sea cuestión abierta, la autenticidad de la Trompa y su atribución a Pérez de Montalbán nos parece segura (véase un resumen de la cuestión y una posición más matizada en Plata, 2017, p. 169n).

29. Un resumen actualizado de las diferentes atribuciones según los diferentes estudiosos en Alonso Veloso, 2017, p. 10 n.

30. Alonso Veloso, 2017, pp. 25 y ss. 
es, él mismo, desaliño andrajoso y extremo de mendiguez, viéndole su talle tan abominable y asqueroso (que en ambas cosas solo se excede a sí mismo, a cuya causa le llaman y es conocido por «el diablo Cojuelo», como también por el de «Patacoja» y «Derrengado»)

En su edición del Tribunal, Victoriano Roncero repasa los apelativos y la caracterización de Quevedo, con cuyos defectos físicos, por supuesto, se ceban los autores del libelo: «es viejo y envejecido en hablar suciedades, siendo su boca un hediondo albañar de pútridos excrementos». Al tratar de El alguacil endemoniado afirman: «iCon cuánta mayor razón se le puede decir a don Francisco de Quevedo (que es el que se opone a esto) autor endemoniado -o demonio autor- que al alguacil que finge que lo estaba!». Así se imaginan a Quevedo los autores del Tribunal en el infierno:

él se hallara, con su pata coja, dislocado de lomos y los ojos atribulados, hechos dos albañares de excrementos, bastantes a dar asco a los mismos diablos, y compitiera (pues tiene por cierto que allí se riñe) con Tersites sobre cuál de los dos era más feo y lo fue en su tiempo, en que ventajosamente quedará vencedor, con haber gozado el otro la primicia de la fealdad ${ }^{32}$.

El retrato de Quevedo en el Tribunal, el del Cojuelo de Vélez, o los del licenciado Calabrés y la dueña Quintañona presentan técnicas compartidas, y especialmente los dos primeros, son igualmente repugnantes. Tal vez el más repugnante - y soez- de todos, el del propio Quevedo; lo distingue la saña de sus enemigos.

\section{La saña de unos viejos enemigos notorios. Censuras e InQuisición}

Aunque no nos interesa dilucidar la autoría del Tribunal, ciertamente será necesario recordar qué papel jugaron Luis Pacheco de Narváez y fray Diego Niseno (pues de Juan Pérez de Montalbán ya nos hemos ocupado). Que Luis Pacheco, el maestro de esgrima (que lo fue de grandes figuras, como Felipe IV o Vélez de Guevara, por poner dos ejemplos), era enemigo de Quevedo queda fuera de toda duda. Aparte de anécdotas que pueden ser legendarias, nos centraremos en lo que aquí nos interesa. Pacheco ya había firmado y presentado en 1630 ante la Inquisición un memorial contra la Política de Dios y los escritos satíricos de Quevedo. Según Juan Ignacio Laguna, la base del memorial firmado por Pacheco

31. Pacheco de Narváez, Tribunal de la justa venganza, p. 77. Se produce cierta confusión entre el personaje del Buscón y el de Quevedo, pero queda clara la referencia por la aposición especificativa («es, él mismo») y por la confirmación del abogado, en el tribunal, cuando después toma la palabra para defender al escritor: "tampoco anda su persona tan mal adornada...» (p. 78). El uso del apodo «diablo Cojuelo» ya señalado por Rodríguez Cepeda y Vivar, 1998, p. 173.

32. Las tres citas en pp. 49 y 116-117; todas comentadas en su introducción por Victoriano Roncero, 2008, p. 30. 
era la enconada y negativa censura que previamente fray Diego Niseno había escrito sobre El discurso de todos los diablos en 1629. Respecto a la censura que había escrito y firmado Niseno sobre el Discurso en 1629, ya nos hemos ocupado en otros lugares, desmenuzaba, como se hace también en el Tribunal de la justa venganza, la sátira quevedesca.

Vamos, pues, con el fraile basilio Diego Niseno. Predicador y figura relevante en la corte, importante e íntimo amigo de Pérez de Montalbán, de cuyo Para todos firmó la aprobación, redactó la demoledora censura de julio de 1629 del Discurso de todos los diablos a la que nos venimos refiriendo, la que sirvió de base tanto para el Memorial que Luis Pacheco de Narváez presentó a la Inquisición, como para sustanciales fragmentos del Tribunal de la justa venganza (en cuya redacción también pudo participar activamente, según ha demostrado María José Tobar, 2010). En su rigurosa y ortodoxa censura reprueba Diego Niseno que el Discurso de todos los diablos sea sátira, sátira muchas veces genérica de estados y profesiones (algo que perseguía la Inquisición) ${ }^{33}$, así como por supuesto, el tomarse a burla diablos e infierno (argumentos que retomaría después el Tribunal de la justa venganza):

digo por mayor que el asumpto de la obra de Todos los diablos es sátira; su principal artificio, hablar del infierno como cosa de burla, como de lugar donde los condenados dicen chistes, gracejan y se entretienen. Esto tiene conocido escándalo, no sólo para los ignorantes, sino para los doctos. [...]

Folio 2, pág. 1: Que tiene Lucifer "guarda de tudescos y alemanes», que el entremetido «hacía cortesías a las almas en el infierno y se voseaba con ellas». Todo es irrisión de los castigos de Dios; ocasión que los tengan por burla los ignorantes.[...]

Folio 11, pág. 1: “ó́game vuestra diablencia». Mucho juega con los demonios. Puédese temer que han de jugar allá mucho con él. Pero si le sucede, allá verá que no es juego. [...]

Desde donde comienza a hablar de Julio César hasta donde dice que Lucifer dividió el infierno en chancillerías es una sátira osada, injuriosa, escandalosa, mal sonante; ocasión al pueblo de menospreciar los superiores. $[\ldots]$

Juzgo que este autor es digno de enmienda; de que se le prohíba escribir en todas materias, que lo que ha escrito se sepulte todo; que no se admita aun después de expurgado, pues dejar correr escritos corregidos es privilegio de los que, estándolo de lo que tienen contra fe y buenas costumbres, enseñan algo de lo que se debe saber y edifican los fieles. Pero los deste autor, cuando más azarandados, siempre son ofensa de los más principales estados de la República cristiana, enseñanza de todo mal y pecar al pueblo ${ }^{34}$.

No hace falta insistir en las posibles y reales consecuencias de esta censura y de las invectivas y operaciones combinadas entre Luis

33. Según Gacto, 1991, p. 38, «la Regla 16 que aparece formulada por vez primera en el Índice de 1640, venía aplicándose con anterioridad en contra de los escritos que descalificaran en bloque a una concreta profesión o a un determinado sector social».

34. Citado a partir de la reproducción en Gacto, 1991, pp. 34-35. 
Pacheco de Narváez, fray Diego Niseno y el notario del Santo Oficio Juan Pérez de Montalbán. No fueron al final tan graves como ellos hubieran deseado, es decir, que se le prohibiera a Quevedo escribir, pero sí se prohibieron varias ediciones de obras suyas y estas hubieron de ser enmendadas, de donde surgió la aberrante edición de los Juguetes de la niñez de 1631; hubo daños, desde luego, pero ante tanta inquina debe valorarse que fueron daños controlados ${ }^{35}$.

Fray Diego Niseno ha estado también en la nómina de los posibles autores de otro libelo antiquevediano, también anterior al Para todos, la Venganza de la Lengua Española contra el autor del Cuento de Cuentos, aunque también se ha atribuido con mayor insistencia a fray Juan Ponce de León, de nuevo por ecos verbales y coincidencias de estilo significativas. Aunque la autoría de Ponce de León de la Venganza, que propuso Gillet en 1936 y asumieron luego Astrana, Buendía y García Valdés, ha sido recientemente descartada por Sandra Valiñas Jar, de lo que no cabe duda es de su autoría de una muy fundamentada jurídicamente y demoledora censura del Cuento de cuentos que se conserva autógrafa en el Archivo Histórico Nacional y que acaba por condenar todos los escritos satíricos de Quevedo, llegando al Buscón. De hecho, el Cuento de cuentos parece una mera excusa para acometer un ataque en toda regla, sobre la base fundamental de la sátira de los eclesiásticos, en el que, después de citar a numerosas autoridades que recomendarían prohibir libros con tales contenidos, por ejemplo, leemos:

en este libro de Quevedo -y en los demás que dolosamente ha impresoson mayores sus sueños que sus vigilias y mucho más la ofensa de sus burlas que la edificación de sus veras, debiendo como religioso noble correrse de poner por interlocutores de deshonestos desatinos a personas constituidas en dignidad de tan santa religión como la de san Francisco, dando lugar a que con ella y con sus hijos se entretenga un vulgo malicioso; teniendo por motivo de burla y mofa la santidad de sus prelados, trayendo en comprobación de sus sueños en el libro del Buscón la devoción fingida de una monja representada con tanta libertad que aun con menos era bastante para ofender a un estado menos religioso, dando con esto ocasión a que los herejes crean que las vanidades que del estado religioso refiere son comunes a todo él y que con aprobación se hacen, pues con licencia se imprimen. Con lo cual, la religión viene a padecer agravio en los seglares, pues estudiando

35. Aunque aquí nos estamos centrando más en la persecución de Quevedo por parte de sus enemigos, no hay que dejar de observar que el satírico era tratado con mano de seda por parte de la Inquisición, y la "solución» que finalmente se le dio al caso pudo dejar satisfechos o insatisfechos, en parte, a todos. A los enemigos, porque habían logrado que el nombre de Quevedo apareciera en el Índice, aunque también podría valorarse que era una victoria pírrica, lo que pudo dejar relativamente tranquilos a quienes intentaban minimizar daños. Sobre estas cuestiones, presenta interés lo dicho sucesivamente por Asensio, 1988, pp. 29 y 32; Gacto, 1991, p. 41, y Ettinghausen, 2010, pp. 307-308. 
arte para ser agudos, aprenden de los libros de Quevedo sus satíricos dichos y escandalosos donaires ${ }^{36}$.

Hay que pensar que la redacción de la contundente y desproporcionada censura de Ponce de León iba más allá, obviamente, del propio Cuento de cuentos (que, dentro de lo que es la potencialidad de la sátira quevedesca, no pretendía más que burlarse del abuso de frases hechas y solecismos), entre otras cosas, porque por esas fechas, 1629, estaba trabajando activamente, con el padre Pineda, en la confección del mencionado Novus Index Librorum Prohibitorum et Expurgatorum de 1632 , según nos dice Ettinghausen ${ }^{37}$.

Circunstancias de la publicación de El diablo Cojuelo en la esteLA DE LAS POLÉMICAS QUEVEDIANAS

Aunque podría parecer que nos hemos desviado por las sendas de Quevedo y nos hemos olvidado ya del Cojuelo, no es así: hemos llegado exactamente al punto que queríamos. Y es que conviene subrayar que estos dos viejos y notorios enemigos de Quevedo, fray Diego Niseno y fray Juan Ponce de León, fueron, precisamente, los que redactaron y firmaron las aprobaciones que autorizaban la publicación de El diablo Cojuelo. No deja de sorprendernos, cuánto contrasta, como observó con mucha razón Enrique Gacto, la condena reprobatoria que ambos emitieron contra las obras de Quevedo, con su laudatoria aprobación de El diablo Cojuelo, que, aunque más prudente en su sátira, no dejaba de enseñarnos diálogos y pactos con el diablo o aludir al entorno religioso como cómplice necesario en la usurpación social, por mencionar sólo algunos aspectos que habrían sido puestos de relieve como inaceptables en Quevedo ${ }^{38}$. Aunque tal vez ese contraste no debería sorprendernos tanto si asumimos lo que dice también Enrique Gacto: «Amistad y ene-

36. Se cita por la reproducción de Valiñas Jar, 2014, pp. 96-97, en apéndice a su edición de la Venganza de la Lengua Española de Juan Alonso Laureles.

37. Ettinghausen, 2010, p. 301.

38. Recuérdese, más allá de toda la novela en su conjunto, el contenido del tranco I, la declaración de cortesía, pero con connotaciones también de pleitesía y servicio de don Cleofás («vuesa merced me conozca por su servidor, que ha muchos días que le deseaba conocer», ed. Valdés, p. 16), o en el tranco ıII, el episodio de la «ropería de los agüelos», donde desde el inicio se deja constancia de la complicidad y beneficio económico de los sacristanes en los procesos de ennoblecimiento y la usurpación de apellidos (ed. Valdés, pp. 40-41: «una calle algo dilatada que por una parte y por otra estaba colgada de ataúdes, y unos sacristanes con sus sobrepellices paseándose junto a ellos, y muchos sepultureros abriendo varios sepulcros [...] Esotro más abajo da por otro agüelo el suyo, y dineros encima, y no se acaba de concertar, porque le tiene más de costa al sacristán»). Dice Gacto, 1991, p. 33, sin dudarlo: “además de abundar en trivializaciones sobre el infierno y los demonios, El Diablo cojuelo bien fácilmente pudiera incurrir en la Regla del Índice condenatoria de la difusión de noticias sobre Nigromancia y artes mágicas; leyéndolo, también el vulgo pudiera creer en la existencia de familiares encerrados en redomas, conjuros, encantamientos, viajes por los aires, etc.». 
mistad resultan así, en el siglo xvII, factores de suma importancia a la hora de emitir dictamen ${ }^{39}$.

La aprobación de fray Diego Niseno para el Cojuelo parece un bofetón en toda regla a Quevedo, con una más que obvia alusión (“este linaje de escritos») a sus sátiras menipeas:

Esta novela que se intitula El diablo Cojuelo, escrita por Luis Vélez de Guevara $[\ldots]$ no sólo no tiene cosa alguna que se oponga al católico sentir de nuestra sagrada fe y buenas costumbres por que se pueda negar la licencia que el autor pide para estamparla, pero antes muchas de mucha moralidad y enseñanza, escritas con la sazón y variedad que de tal ingenio se podía esperar. Merece la licencia que pide porque este linaje de escritos es difícil de encuadernar con lo honesto y recatado de nuestras cristianas leyes, y Luis Vélez ha sido en éste gloriosa excepción desta universal dolencia, pues entretiene sin ofender y enseña sin escandalizar. Este es mi parecer. En San Basilio de Madrid, setiembre, 5, de $1640^{40}$.

Podría ser interesante discutir lo que dice Niseno (en definitiva, comparar en esos términos la sátira de Vélez y de Quevedo), aunque con mucha probabilidad estuvo más condicionado por intereses, filias y fobias personales que por un verdadero espíritu constructivo cumpliendo su papel de censor en el terreno literario, religioso y político (en su sistema de valores) y no hay aquí espacio para ello. Con todo, desde luego, la sátira menipea de Vélez, por más honesta y menos escandalosa que fuera, presentaba también los aspectos delicados para su aprobación que destacó Enrique Gacto y que son casi inherentes al género ${ }^{41}$, como de hecho observaba con acierto Niseno.

En el contexto que venimos presentando, que los censores del Cojuelo fueran dos antiguos y notorios enemigos de Quevedo no parece casual. Como tampoco debe de serlo que la empresa de editar esta novela de la otra vida fuera costeada por Alonso Pérez, padre de Juan Pérez de Montalbán, y que la impresión se llevara a cabo en la Imprenta del Reino. Alonso Pérez e Imprenta del Reino fue el pie que figuró en el Para todos de Juan Pérez de Montalbán (con aprobaciones de José de Valdivielso y de fray Diego Niseno; como recuerda Cayuela, Quevedo afeó el hecho de que Niseno fuera a la vez dedicatario del «día v» del libro), pero también con dicho pie se publicó la Historia ejemplar de las dos constantes mujeres españolas de Luis Pacheco de Narváez o, la Fama pósthuma de Lope de Vega que escribió y coordinó Juan Pérez de Montalbán o, a la prematura muerte de éste, el Elogio evangélico funeral en el fallecimiento del doctor Juan Pérez de Montalbán a cargo de fray Diego Niseno.

Anne Cayuela anota en su monografía sobre Alonso Pérez que

39. Gacto, 1991, p. 33.

40. Vélez, El diablo Cojuelo, ed. Valdés, p. 4.

41. Sobre la sátira menipea elaborada por Quevedo en un contexto de Contrarreforma católica y qué riesgos implica, véanse las consideraciones de Crosby, 2001, pp. 111-117; Valdés, 2013, pp. 243-244, y 2016, pp. 239 y 252-253. 
las ediciones financiadas por nuestro editor desvelan una práctica algo «irregular» de la censura previa. En efecto, un grupo que pertenece a los círculos literarios, formado por los adeptos o amigos de Lope, monopoliza de manera manifiesta la actividad censora, y la elección casi sistemática de unos cuantos individuos deja percibir una connivencia entre autores y censores y quizás entre censores y editores. Estos mismos nombres aparecen también en los preliminares literarios como autores de poesías laudatorias ${ }^{42}$.

Apuntemos otro par de datos reseñables. Uno, respecto a lo que comenta Cayuela de las poesías laudatorias preliminares: entre las que se incluyeron en la novela de Luis Pacheco de Narváez en 1635 hubo sonetos y décimas de Lope de Vega, Valdivielso, Pérez de Montalbán, Calderón, Ruiz de Alarcón y, entre algunos más, uno de Luis Vélez de Guevara ${ }^{43}$. Cuando murió en 1635 Lope de Vega, obviamente al ser Juan Pérez de Montalbán el recolector de composiciones, Francisco de Quevedo no pudo participar en el homenaje, aunque sí lo pudo hacer, claro, Vélez de Guevara, al que acompañaron otros ingenios entonces en boga en la corte, como Antonio Hurtado de Mendoza, Alfonso de Batres o Francisco de Rojas, a los que se encargaban comedias, vejámenes y academias burlescas; eventos y ambientes con los que en cierto modo también se puede relacionar la génesis de El diablo Cojuelo.

Fernando Plata (2017) ha rastreado recientemente los testimonios de las relaciones entre Francisco de Quevedo y Luis Vélez de Guevara entre 1608 y 1632. De hecho, en el año 1632 coinciden ambos con composiciones en determinados libros de circunstancias y Quevedo, en La Perinola, acaba por ensalzar a Vélez, pues lo coloca entre los grandes cuando le aconseja a Pérez de Montalbán que «deje las novelas para Cervantes; y las comedias a Lope, a Luis Vélez, a don Pedro Calderón y a otros» ${ }^{44}$. Fernando Plata, prudentemente, relativiza el valor de ciertos elogios y participación en homenajes, y no quiere dar carácter definitivo y probatorio de amistad a coincidencias en esos contextos, aunque sí podrían considerarse un indicio de una relación cordial ${ }^{45}$. También, muy prudentemente, se preocupa de dejar claro que sus indagaciones llegan hasta 1632. Tal vez ese año -motivos hubo- se produjo un giro, y del mismo modo que antes habían sido amigos Quevedo y Pérez de Montalbán, pudieron cambiar las tornas entre Quevedo y Vélez con el paso del tiempo y los conflictos. Desde luego es cierto (y de hecho el mismo Plata lo subraya ${ }^{46}$ ) que algunas complicidades y coincidencias

42. Cayuela, 2005, p. 53. Según ha podido atestiguar Bouza, 2012, pp. 77-80, la práctica, más que irregular, era permitida y queda rastro en los archivos de ella. Tanto editores como incluso autores podían solicitar al Consejo de Castilla que actuaran determinados censores (o también podían recusarlos).

43. Véase Laguna, 2016, p. $261 \mathrm{n}$.

44. Quevedo, Prosa festiva completa, ed. García Valdés, p. 507.

45. Plata, 2017, pp. 283-284.

46. Plata, 2017, p. 284 y n. 
de Vélez con los enemigos de Quevedo llaman la atención; las que aquí hemos visto se concentran todas después del hito de 1632.

Ciertamente, si Vélez llevó el Cojuelo a Alonso Pérez para que lo costeara, la elección de los censores - si es cierta la connivencia que señala Cayuela- pudo depender ya del librero. Sin embargo, aunque esto fuera así, el solo hecho de dirigir sus pasos a Alonso Pérez, y toda la ristra de coincidencias y complicidades que hemos visto con la camarilla del Tribunal de la Justa Venganza, ¿podía ser también casual e inocente? ¿Por qué no aparece composición alguna de Quevedo en la Fama pósthu$m a$ ? Evidentemente, algún peso y significado se les otorgaban a esos gestos. Y conviene señalarlos, en un sentido o en otro, como ha hecho Fernando Plata en su artículo o como hacemos aquí ahora.

¿Pudo haber intencionalidad en la elección del personaje del Cojuelo y pudo funcionar como alusión a Quevedo? ¿Pudo ser el El diablo Cojuelo, novela de la otra vida una respuesta, una réplica, una continuación literaria, de alguna manera, de la obra de Quevedo? ¿Pudo esconder una pulla cordial y cómplice o una burla maliciosa al satírico, por entonces encarcelado?

¿El diablo Cojuelo como posible alusión a Quevedo y clave de LECTURA DE LA NOVELA DE VÉLEz?

Muchos hechos y datos contextuales que se han apuntado favorecen que nos planteemos la cuestión del titulillo de este apartado, aunque convendrá hacerlo y dejarlo así, como una cuestión abierta. Aparte de lo que hemos visto en el contexto, procede ahora observar y plantear la importancia de algunos elementos en el texto.

El primero y más importante es el que ya hemos mencionado, es decir, la coincidencia entre el personaje protagonista elegido por Vélez y el apodo aplicado a Quevedo por sus contemporáneos, no sabemos si de forma más restringida entre los enemigos o más divulgada y generalizada ${ }^{47}$. Más allá de los nexos entre Quevedo y el diablo Cojuelo ya vistos y que justifican ese apodo $\mathrm{y}$, por tanto, también la plausible identificación de persona / figura folclórica, es decir, su cojera ${ }^{48}$ y su carácter burlón e ingenio, su rebeldía, podemos ver ahora otros aspectos.

Otra coincidencia que podría resultar muy relevante a favor de la identificación entre el personaje real de Quevedo y el literario del Cojuelo en la novela de Vélez es que este se presente preso en una redoma y el primero estuviera en prisión en el momento de la redacción y la publicación de la obra, como muy bien destacaron Rodríguez

47. Recuérdese el fragmento ya citado de El tribunal de la Justa Venganza: «a cuya causa le llaman y es conocido por "el diablo Cojuelo", como también por el de "Patacoja" y "Derrengado"» (p. 77).

48. Por cierto, ambos, Cojuelo y Quevedo, en su autopresentación, se declaran por su cojera «señalado de la mano de Dios»: Luis Vélez, Diablo Cojuelo, p. 16; Quevedo, Memorial que dio en una academia, p. 174. 
Cepeda y Vivar ${ }^{49}$. Recuérdese que El diablo Cojuelo se publica en 1641, aunque debía estar ya acabado antes del 5 de septiembre de 1640, fecha de la aprobación de fray Diego Niseno, precisamente. Quevedo estaba en prisión en el convento de San Marcos de León desde prácticamente un año antes, inicios de diciembre de $1639^{50}$. Si quisiéramos seguir este hilo, cabría añadir que, si el Cojuelo es figura de Quevedo, también se podría entender perfectamente que ese astrólogo nigromante que lo tiene preso es el conde-duque de Olivares. Y ahí cabría también recordar la fama que, en los últimos tiempos, y especialmente tras su caída (aunque ya corrían rumores desde bastante antes), se divulgó del conde-duque de Olivares como interesado en cuestiones mágicas y astrológicas (hasta el punto de presentarlo como nigromante), creencias que resumió en deliciosas páginas Gregorio Marañón en su biografía del privado $^{51}$. Ya aquí tendríamos una posible clave de lectura. Pero téngase claro que no la defendemos, sino que sólo la planteamos ${ }^{52}$.

Por otro lado, siguiendo con la figura de Quevedo, más allá de los rasgos compartidos con el Cojuelo ya comentados, podría interesar mencionar otros que tal vez no son tan obvios. Así, el Cojuelo se define, a pesar de su cojera, cágil para todas las facciones que se ofrecen en los Países Bajos», aludiendo con doble sentido tanto a sus facultades sexuales, como a su carácter cizañero, que eran rasgos con que se autodefinía, también con vanidad, el propio Quevedo, que se defendía devoto de monjas, y se postulaba para el Cabildo del Regodeo, de vida desordenada, dado a la carne, diestro en jugar las armas «y otros juegos». Por estas aficiones era duramente criticado en el Tribunal de la justa venganza: «manifestó su torpe y lasciva lengua lo insaciable de su lujuria y el exceso de la sensualidad ${ }^{53}$. Respecto al carácter cizañero que lleva al Cojuelo a meterse en múltiples peleas, siempre pronto al conflicto (lo que podemos ver un tranco tras otro), el propio Quevedo se jactaba de tener «natural acreditado y belicoso para tan facinerosos distraimientos» en la dedicatoria a Su espada por Santiago ${ }^{54}$. De este natural belicoso en cierto modo podía derivar otro, que es su afán de participar de cualquier acontecimiento de interés del momento, o dicho en términos del diablo: «me meto en todo: yo soy las pulgas del infierno, la chisme, el enredo..., ${ }^{55}$. Así, el Cojuelo, a lo largo de la novela, participa en cuanto conflicto puede, y por aquello de que «Quien

49. Rodríguez Cepeda y Vivar, 1998, p. 174.

50. Véase Crosby, 1997, pp. 102 y ss.

51. Véase ahora Lara Alberola, 2015

52. Para posibles interpretaciones del sentido del Cojuelo, véase un resumen en Valdés, 1999, XLVII-LVIII, con un examen de lecturas «en clave» propuestas por Rodríguez Cepeda en p. LIV y n. La línea que aquí seguimos, ya apuntada en Rodríguez Cepeda y Vivar, 1998, parece incompatible con anteriores propuestas de lectura en clave de Rodríguez Cepeda, aunque insisten en ellas en ese mismo artículo en p. 175.

53. Pacheco, Tribunal de la justa venganza, p. 79.

54. Quevedo, Su espada por Santiago, citado por Candelas Colodrón, 2014, p. 118.

55. Vélez de Guevara, El diablo Cojuelo, ed. Valdés, p. 15. 
da luego, da dos veces), no duda si le toca comenzarlas. Lo mismo se enzarzan en la pelea de una compañía de comedias, que en una trifulca que se monta en un garito de pobres, una pelea de ciegos o lo que se tercie, siempre desencadenando la risa en el lector. Pero lo que aquí nos interesaba, para acabar con otro episodio que podría percibirse «en clave» es ese viaje que el diablo Cojuelo hace una noche, mientras don Cleofás duerme, para revolver un poco el mundo. En esa sola noche vuela hasta Turquía y, tras volver disfrazado «con el traje del país», le explica a don Cleofás - al inicio del tranco v- su viaje por los Cantones de Suiza, la Valtellina y Ginebra, acabando por fin en Venecia, enredando en cuestiones de espías:

Fui a Venecia, por ver una población tan prodigiosa que está fundada en el mar, y de su natural condición tan bajel de argamasa y sillería que, como la tiene en peso el piélago Mediterráneo, se vuelve a cualquier viento que le sopla. Estuve en la plaza de San Marcos platicando con unos criados de unos clarísimos esta mañana $y$, hablando en las gacetas de la guerra, les dije que en Constantinopla se había sabido, por espías que estaban en España, que hay grandes prevenciones della, y tan prodigiosas que hasta los difuntos se levantan, al son de las cajas, de los sepulcros para este efecto, y hay quien diga que entre ellos había resucitado el gran duque de Osuna; y apenas lo acabé de pronunciar, cuando me escurrí por no perder tiempo en mis diligencias ${ }^{56}$.

No hace falta seguir. Uno de los aspectos de la vida de Quevedo aquilatados por Paolo Tarsia fueron sus servicios como agente de la Corona, que le granjearon en sus nueve años italianos, plagados de viajes y misiones relámpago por mar y tierra, numerosos riesgos y enemigos. En este fragmento se evidenciaría, de nuevo, una posible intención de aludir a través de la figura del Cojuelo a Francisco de Quevedo, con sus reales o legendarias aventuras participando como espía en la conjura de Venecia acompañado de Jaque Pierres y de un español genízaro (recuérdese que el Cojuelo llega «en traje turquesco») de la que huyó disfrazado de pobre harapiento, según el tempranísimo relato de su biógrafo ${ }^{57}$; Castellani, que también insinúa en su Castigo esemplare la participación del poeta en la conjura, lo retrataba como nigromante capaz de convertir al duque de Osuna, para complacerlo, en lobo, en cerdo, en tigre, o transportarlo entre lugares distantes o darle diferentes apariencias humanas ${ }^{58}$. Están todos los elementos: la conversación en italiano, el disfraz, la huida, las artes mágicas, la mención a Osuna. Por cierto, si al cándido lector de la novela (o al moreno y escéptico ante este artículo) no le quedara clara la vinculación, será bueno recordarle que al inicio de este episodio le dice el estudiante al Cojuelo entre pu-

56. Vélez de Guevara, El diablo Cojuelo, ed. Valdés, p. 55.

57. Véase ahora a este respecto Cappelli, 2017, con la bibliografía imprescindible y la más reciente.

58. Citado por Cappelli, 2011, p. 48. 
llas: «Bien sé que sabes Filosofía -le dijo don Cleofás- mejor que si la hubieras estudiado en Alcalós. La presencia de Quevedo en la conjura de Venecia, según nos explica Federica Cappelli, empezó a convertirse en leyenda, incluso en motivo folclórico desde el mismo momento de los hechos de 1618:

A pesar de esto, la supuesta presencia de Quevedo en Venecia en los días de la conspiración se convirtió enseguida en auténtica leyenda, incluso en motivo folclórico, a cuya difusión contribuyó mucho, en aquel momento, el citado libelo antiespañol, Castigo essemplare de' Calunniatori (1618), donde el autor denuncia, si bien indirectamente, la implicación del poeta en el complot $^{59}$.

Qué intención pudiera albergar Vélez en la creación de su personaje y novela, si los concibió con Quevedo en la cabeza desde un principio, o si alguna alusión -de ser acertadas estas hipótesis- surgió accidentalmente por el camino, no lo sabemos con seguridad. Tampoco si esas alusiones, de ser tales, podían albergar intenciones ofensivas o meramente ingeniosas y literarias, incluso de homenaje. Vélez, según lo describen sus contemporáneos, era colmo de la amabilidad, urbanidad y cortesanía.

Si hubo intención de aludir, más allá del apodo a Quevedo como “diablo Cojuelo», con el que tampoco salía tan mal parado el escritor madrileño - el diablo Cojuelo, aparte de cojo, es simpático e inteligente-, tal vez podría resultar más denigrante o cruel el hecho de establecer la prisión (Quevedo en prisión = Cojuelo en redoma) como uno de los términos de la burla y nexos para la identificación. Con todo, en descargo de Vélez, se podría pensar que, a esas alturas, cuando él escribió El diablo Cojuelo, todavía no se sabía que la prisión iba a prolongarse tanto y resultar tan dura que llevaría a Quevedo hasta las puertas de la muerte. Pero, de todo, lo que parecería más difícil de digerir, y lo que, si hubo ánimo de ofensa, más pudo doler tal vez a Quevedo, fue que, ese dramaturgo que se metió a satírico en prosa por una vez, imitando sus Sueños y sus discursos (por mucho que la novela del ecijano tenga otros méritos), obtuviera sin dificultad alguna unas aprobaciones firmadas precisamente por aquellos que a él, por esas mismas obras, tantos disgustos le ocasionaron. Quevedo tuvo que sufrir, muy diversamente, no solo la humillación de que su nombre apareciera en el Índice, sino que además se le obligara a renegar de sus Sueños y discursos y a publicar, con su autorización forzada, la aberración literaria y estética de los Juguetes de la niñez. Eso sí debió doler.

A día de hoy, desde luego, si las hipótesis aquí planteadas son ciertas, y hubo intención de aludir, resulta difícil no ver, dadas las circunstancias de Quevedo, en prisión, cierto grado de crueldad o cuando menos, en caso de que fuera un homenaje ingenioso y medio en broma, desconsideración o falta de empatía. Cierto es que, para casos como

59. Cappelli, 2017, p. 27. 
estos e incluso de claros y públicos insultos y enfrentamientos, como el de Quevedo con Pérez de Montalbán, Diego Niseno o con Góngora, o entre éste y Lope, la crítica ha insistido en quitarles importancia, por ser habituales en la época y formar parte de las reglas del juego, unos códigos que todos conocían (Candelas, 2014). Con todo, no se puede excluir que en estos juegos alguien, incluso alguien tan acostumbrado a ellos, como Quevedo, pudiera sentirse ofendido.

\section{RECAPITULACIÓN Y CONCLUSIÓN}

Si los testimonios que tenemos de que a Quevedo se le apodaba «Diablo Cojuelo» reflejan un fenómeno realmente extendido, parece difícil que, ante los paralelismos y puntos de contacto aquí aducidos, no se asociara al satírico madrileño esta "novela de la otra vida», titulada con su apodo, desarrollada en su género y estilo, y con los puntos de contacto señalados. Lo apuntaba maliciosamente el propio Niseno en su preceptiva aprobación al aludir a (este linaje de escritos»: sobre esto prácticamente no cabe duda.

Hay que entender que la novela misma, si ostentaba un apodo intencionado en su título, se sustentaba sobre los principios del arte de motejar. Por eso, lógicamente, si hay intención de motejar, de aludir a través del título y el protagonista, se establecen una serie de vínculos entre el personaje de ficción y folclórico del Cojuelo y la figura que está a medio camino entre la ficción, la leyenda, el folclore y la realidad del propio Francisco de Quevedo (cojera, lascivia, ingenio y capacidad satírica y cizañera, artes mágicas), a través de sus circunstancias (en la redoma; en prisión), historias y aventuras (estudios en Alcalá, espías y chismes, y episodio de Venecia). Pero Vélez no es un bufón ni lo que escribe es El tribunal de la justa venganza. Su obra es distinta. El tribunal insultaba y atacaba directamente. Vélez, maestro de urbanidad y cortesanía debe ser más sutil en su arte de motejar, como sutil debe ser el escritor y el lector de la literatura barroca. El oficio consiste en transmitir, pero no abierta y groseramente, sino aludir y eludir, jugar también con mecanismos de ocultación, y con ese juego y el desvelamiento e intelección del mensaje disfruta también el lector ${ }^{60}$. El vínculo no puede resultar evidente, y eso obliga a que, en nuestra labor hermenéutica, interpretemos, más allá de lo obvio, lo sutil.

Y, por otro lado, más allá de los elementos de apoyatura para una lectura en clave que ofrece el texto y que hemos referido en el párrafo anterior, también se debe prestar atención a los datos objetivos del contexto. Y si los elementos textuales no parecieran suficientes, las circunstancias de la publicación de El diablo Cojuelo invitan también, cuando menos, a la reflexión. Resulta más que llamativo el hecho de que se imprimiera a costa de Alonso Pérez, en la Imprenta del Reino,

60. Blanco, 1988. 
con su historial de escritos antiquevedescos, y que redactaran sus elogiosas aprobaciones precisamente fray Diego Niseno y Juan Ponce de León, que se habían distinguido por redactar asimismo las más acerbas y negativas censuras de las sátiras menipeas de Quevedo que, paradójicamente, habían servido de modelo a Vélez. Parecen ya demasiadas casualidades que en cualquier caso conviene recordar.

Todo ello resulta reseñable y ofrece, en conclusión, una base para el planteamiento, al menos, de una hipótesis de lectura en clave: El diablo Cojuelo podría encerrar, en el apodo que alude al protagonista y da título a la novela, así como en los paralelismos que implican algunos pasajes y circunstancias, una alusión a la figura real y ya por entonces encaminada a convertirse en legendaria y folclórica de Francisco de Quevedo.

Paradójicamente, había sido el propio Quevedo quien, en su autorrepresentación en su prosa satírica y burlesca de juventud, había creado las bases para lo que luego fue ese proceso de conversión en figura de ficción e incluso en figura folclórica y su posible asimilación por parte de Vélez a la figura folclórica del diablo Cojuelo.

\section{CodA}

Ahí están ambas figuras, Quevedo y el Cojuelo, como figuras folclóricas o con fuerte presencia en el ámbito imaginario y de ficción ${ }^{61}$. Todavía hoy Quevedo inspira literatura y muchos de sus rasgos son tipificados. También es una figura folclórica, un espíritu burlón, ingenioso, simpático dentro de lo gruñón y rebelde, un trickster, asimilable al Cojuelo en algunos rasgos y actitudes. Pero a la vez es un personaje literario con su propio bagaje ficcional y su propia fuerza que traspasó tiempos y fronteras y, en la actualidad, sigue plenamente vivo. Desde el Hospital das letras, de 1657, de Francisco Manuel de Melo hasta el recentísimo personaje de un Quevedo moribundo incorporado por el actor Juan Echanove en una dramaturgia de Gerardo Vera a partir sobre todo de los Sueños, que daban título al montaje en una producción de la Compañía Nacional de Teatro Clásico de la temporada 2017 / 2018. Pero mayor interés tiene todavía para el tema que nos ha ocupado otra creación escénica también reciente, La escuela de los vicios, una dramaturgia de Francisco Negro sobre la base de textos de Francisco de Quevedo que fue puesta en escena por Morfeo Teatro en 2014 y que protagoniza un personaje llamado Diablo Cojuelo. Su propuesta artística avala nuestras hipótesis científicas. Algo en común tienen y tuvieron don Francisco y el Cojuelo.

\section{Bibliografía}

Alonso Asenjo, Julio, "Caricatura del diablo a base de apodos y matracas en la "Tragedia Ocio" del P. Cigorondo (Puebla, 1586)", en Locos, figurones 
y quijotes en el teatro de los Siglos de Oro. Actas selectas del XII Congreso de la Asociación Internacional de Teatro Español y Novohispano de los Siglos de Oro: Almagro, 15, 16 y 17 de julio de 2005, coord. Germán Vega García-Luengos y Rafael González Cañal, Almagro, Ediciones de la Universidad de Castilla La Mancha, 2007, pp. 55-70.

Alonso Veloso, María José, «Noticia sobre un manuscrito de El tribunal de la justa venganzan, Revista de Filología Española, 97, 2017, pp. 9-34.

Arellano, Ignacio, Poesía satírico burlesca de Quevedo, Pamplona / Madrid / Frankfurt am Main, Universidad de Navarra / Iberoamericana / Vervuert, 2003.

Asensio, Eugenio, "Censura inquisitorial de libros en los siglos xvI y xvII. Fluctuaciones. Decadencia), El libro antiguo español. Actas del primer Coloquio Internacional (Madrid, 18 al 20 de diciembre de 1986), ed. María Luisa LópezVidriero y Pedro M. Cátedra, Salamanca, Ediciones de la Universidad de Salamanca, 1988, pp. 21-36.

Azaustre, Antonio, (ed.), Francisco de Quevedo, Memorial que dio en una academia pidiendo plaza, ed. Antonio Azaustre, en Obras completas en prosa, dir. Alfonso Rey, Madrid, Castalia, 2007, vol. II, tomo I, pp. 149-178.

Beccaria, Gian Luigi, I nomi del mondo. Santi, demoni, folletti e le parole perdute, Torino, Einaudi, 1995.

Blanco, Mercedes, «El mecanismo de la ocultación. Análisis de un ejemplo de agudeza», Criticón, 43, 1988, pp. 13-36.

Bouza, Fernando, "Dásele licencia y privilegio». Don Quijote y la aprobación de libros en el Siglo de Oro, Madrid, Akal, 2012.

Candelas Colodrón, Manuel Ángel, «El Quevedo del Tribunal de la Justa Venganza), Bulletin hispanique, 116, 2014, pp. 107-120.

Cappelli, Federica, «La República de Venecia... (1617) y el Castigo esemplare de” calunniatori (1618): ¿una contienda político-literaria entre Francisco de Quevedo y Giacomo Castellani?», La Perinola, 15, 2011, pp. 37-55.

Cappelli, Federica, «Hacia una definición del papel de Quevedo en Italia», La Perinola, 21, 2017, pp. 17-40.

Cayuela, Anne, Alonso Pérez de Montalbán. Un librero en el Madrid de los Austrias, Madrid, Calambur, 2005.

Crosby, James O., «La última prisión de Quevedo: documentos atribuidos, atribuibles y apócrifos», La Perinola, 1, 1997, pp. 101-124.

Crosby, James O., "Más he querido atreverme que engañarme": Quevedo frente al dilema de hablar o callarse en Los sueños,, La Perinola, 5, 2001, pp. 109-124.

Delpech, François, «En torno al diablo cojuelo: demonología y folklore», en $E l$ diablo en la Edad Moderna, ed. James S. Amelang y María Tausiet Carlés, Madrid, Marcial Pons, 2004, pp. 99-131.

Delpech, François, «Vélez de Guevara, El diablo Cojuelo et le conte folklorique», en El cuento folclórico en la literatura y en la tradición oral, ed. Marta Haro Cortés y Rafael Beltrán Llavador, Valencia, Servei de Publicacions de la Universitat de València, 2006, pp. 111-150.

di Pinto, Elena, "Galería de retratos: figura, figurilla y figurón», Locos, figurones y quijotes en el teatro de los Siglo de Oro. Actas selectas del XII Congreso de la Asociación Internacional de Teatro Español y Novohispano de los Siglos de Oro, (julio 2005, Almagro), coord. Germán Vega García-Luengos y Rafael González Cañal, Almagro, Ediciones de la Universidad de Castilla La Mancha, 2007, pp. 99-110. 
Ettinghausen, Henry, «Quevedo, ¿un caso de doble personalidad?», en HHomenaje a Quevedo. Actas de la II Academia Literaria Renacentista. Universidad de Salamanca, 10, 11 y 12 de diciembre, 1980, ed. Víctor García de la Concha, Salamanca, Ediciones de la Universidad de Salamanca, 1982, pp. 27-44.

Ettinghausen, Henry, «Enemigos e inquisidores: los Sueños de Quevedo ante la crítica de su tiempom, en Literatura, sociedad y política en el Siglo de Oro, ed. Eugenia Fosalba y Carlos Vaíllo, Bellaterra / Gerona, Universitat Autònoma de Barcelona / Universitat de Girona (Studia Aurea Monográfica), 2010, pp. 297-318.

Ettinghausen, Henry, “"El diablo anda suelto”: sátira y burla en las cartas de Quevedo al duque de Osuna», en Estudios sobre Quevedo y la sátira en el siglo XVII, ed. Carlos Vaíllo y Ramón Valdés, Barcelona, PPU, 2011, pp. 1-22.

Gacto Fernández, Enrique, «Sobre la censura literaria en el s. xviI: Cervantes, Quevedo y la Inquisición», Revista de la Inquisición, 1, 1991, pp. 11-61.

Gutiérrez, Carlos M., La espada, el rayo y la pluma. Quevedo y los campos literario y de poder, West Lafayette, Purdue University Press, 2005a.

Gutiérrez, Carlos M., «Narrador, autor y personaje: facetas de la autorrepresentación literaria en Góngora, Lope, Cervantes y Quevedo», Espéculo. Revista de estudios literarios, 31, 2005b, publicación en línea.

Jauralde Pou, Pablo, Francisco de Quevedo (1580-1645), Madrid, Castalia, 1998.

Jiménez Montalvo, María del Mar, «Una pequeña colección de chistes de Quevedo", Revista de Estudios del Campo de Montiel, 2, 2011, pp. 129-141.

Lara Alberola, Eva, «El conde-duque de Olivares: magia y política en la corte de Felipe IV», Studia Aurea, 9, 2015, pp. 565-594.

Laureles, Juan Alonso, Venganza de la Lengua Española contra el autor del "Cuento de cuentos», ed. Sandra Valiñas Jar, Zaragoza / Huesca / Teruel, Prensas de la Universidad de Zaragoza / Instituto de Estudios Altoaragoneses / Instituto de Estudios Turolenses, 2014.

Pacheco de Narváez, Luis, El tribunal de la justa venganza, ed. Victoriano Roncero, Pamplona, Eunsa, 2008.

Patricio, Germán de, «Recepción diacrónica de Quevedo: manipulador manipulado, símbolo colectivom, La Perinola, 15, 2011, pp. 191-234.

Patricio, Germán de, «Nuevos apuntes para la recepción diacrónica de Quevedo», La Perinola, 18, 2014, pp. 321-350.

Pedrosa, José Manuel, “El Diablo Cojuelo en América y África: de las mitologías nativas a Rubén Darío, Nicolás Guillén, y Miguel Littín», Rivista di Filología e Letterature Ispaniche, IV, 2001, pp. 69-84.

Pedrosa, José Manuel, «Esopo, Dante, Giotto, Camões, Quevedo, Bocage, Pushkin... y Bajtin (o la metamorfosis del autor en personaje)", Literary Research / Recherche littéraire, 39-40, 2003, pp. 179-191.

Pedrosa, José Manuel, «Versiones literarias del mito de El Diablo Cojo en Shakespeare, Goethe, Tolstoi, Kipling, Rego, Valle-Inclán, Cela y Galeano», en La literatura en la literatura. Actas del XIV Simposio de la Sociedad de Literatura General y Comparada, coord. Magdalena León Gómez, Madrid, Centro de Estudios Cervantinos, 2004, pp. 551-562.

Pedrosa, José Manuel «Los cuentos de Yohá: tradiciones sefardí, árabe-islámica y universal», en Judeo Espagnol: Social and cultural life in Salonika through judeo-Spanish Texts, ed. Rena Molho, Tesalónica, Ets Ahaim Foundation, 2008, pp. 111-119. 
Pérez de Montalbán, Juan, Trompa del doctor Juan Pérez de Montalbán contra La Perinola de don Francisco de Quevedo, diablo Cojuelo, jorobado y con cuatro ojos, en Obra no dramática, ed. José Enrique Laplana, Madrid, Ediciones de la Fundación José Antonio de Castro, 1999.

Plata Parga, Fernando, «La polémica en torno a La Perinola de Quevedo con un texto inédito", La Perinola, 10, 2006, pp. 245-255.

Plata Parga, Fernando, «La transmisión textual de La Perinola de Quevedo», en Quevedo en su contexto europeo. Política y Religión. Traducciones y textos burlescos, ed. María José Alonso Veloso, Vigo, Editorial Academia del Hispanismo, 2017, pp. 165-184.

Quevedo, Francisco de, Historia de la vida del Buscón llamado Pablos, ejemplo de vagamundos y espejo de tacaños, ed. Pablo Jauralde Pou, en Obras completas en prosa, dir. Alfonso Rey, Madrid, Castalia 2007, vol. II, tomo II, pp. 527-670.

Quevedo, Francisco de, Memorial que dio en una academia pidiendo plaza, ed. Antonio Azaustre, en Obras completas en prosa, dir. Alfonso Rey, Madrid, Castalia, 2007, vol. II, tomo I, pp. 149-178.

Quevedo, Francisco de, Prosa festiva completa, ed. Celsa Carmen García Valdés, Madrid, Cátedra, 1993.

Quevedo, Francisco de, Su espada por Santiago, ed. Manuel Ángel Candelas Colodrón, Obras completas en prosa, dir. Alfonso Rey, Madrid, Castalia, 2015, vol. vi, pp. 165-276.

Quevedo, Francisco de, Sueños y discursos de verdades soñadas descubridoras de abusos, vicios y engaños en todos los oficios y estados del mundo, ed. Ignacio Arellano, en Obras completas en prosa, dir. Alfonso Rey, Madrid, Castalia, 2003, vol. I, tomo I, pp. 185-467.

Quevedo, Francisco de, Vida de corte y oficios entretenidos de ella, ed. Antonio Azaustre, en Obras completas en prosa, dir. Alfonso Rey, Madrid, Castalia, 2007, vol. II, tomo I, pp. 291-347.

Rodríguez Cepeda Enrique y Enrique Rull, (ed.), Luis Vélez de Guevara, El diablo Cojuelo, Madrid, Alcalá, 1968.

Rodríguez Cepeda, Enrique y Francisco Vivar, «Quevedo en el espectro de El diablo cojuelo de Luis Vélez (la clave del Para todos de Pérez Montalbán)», Edad de Oro, 17, 1998, pp. 169-176.

Rodríguez Cuadros, Evangelina, «Alzando las figuras. Hacia una sistematización de lo grotescom, en El figurón. Texto y puesta en escena, ed. Luciano García Lorenzo, Madrid, Fundamentos, 2007, pp. 71-106.

Romanos, Melchora, "Sobre la semántica de "figura" y su tratamiento en las obras satíricas de Quevedo», Actas del séptimo Congreso de la Asociación Internacional de Hispanistas, celebrado en Venecia del 25 al 30 de agosto de 1980, Roma, Bulzoni, 1982, pp. 903-911.

Roncero, Victoriano, (ed.), Luis Pacheco de Narváez, El tribunal de la justa venganza, Pamplona, Eunsa, 2008.

Suárez de Figueroa, Cristóbal, El pasajero, ed. Isabel López Bascuñana, Barcelona, PPU, 1988, 2 vols.

Tobar Quintanar, María José, «La huella de Diego Niseno en El tribunal de la justa venganzan, Boletín de la Real Academia Española, 90, 2010, pp. 131-159.

Valdés, Ramón, (ed.), Luis Vélez de Guevara, El diablo Cojuelo, Crítica, Barcelona, 1999.

Valdés, Ramón, «El otro mundo en las sátiras menipeas de Quevedo. Una evolución a merced de la censura», en Las razones del censor. Control ideológico 
y censura de libros en la primera Edad Moderna, ed. Cesc Esteve, Barcelona, Universitat Autònoma de Barcelona, 2013, pp. 239-262.

Valdés, Ramón, «Francisco de Quevedo por las sendas de la sátira menipea», $L a$ Perinola, 20, 2016, pp. 221-270.

Valiñas Jar, Sandra, (ed.), Juan Alonso Laureles, Venganza de la Lengua Española contra el autor del "Cuento de cuentos», Zaragoza / Huesca / Teruel, Prensas de la Universidad de Zaragoza / Instituto de Estudios Altoaragoneses / Instituto de Estudios Turolenses, 2014.

Vélez de Guevara, Luis, El diablo Cojuelo, ed. Enrique Rodríguez Cepeda y Enrique Rull, Madrid, Ediciones Alcalá, 1968.

Vélez de Guevara, Luis, El diablo Cojuelo, ed. Ignacio Arellano y Ángel Raimundo Fernández, Madrid, Castalia, 1988.

Vélez de Guevara, Luis, El diablo Cojuelo, ed. Ramón Valdés, Barcelona, Crítica, 1999.

Vélez-Sainz, Julio, "Quevedo resting on his laurels: A (Topo)graphical Topos in El Parnasso español,, en Writing for the Eyes in the Spanish Golden Age, ed. Frederick de Armas, Lewiston (PA), Bucknell University Press, 2005, pp. 257-278. 



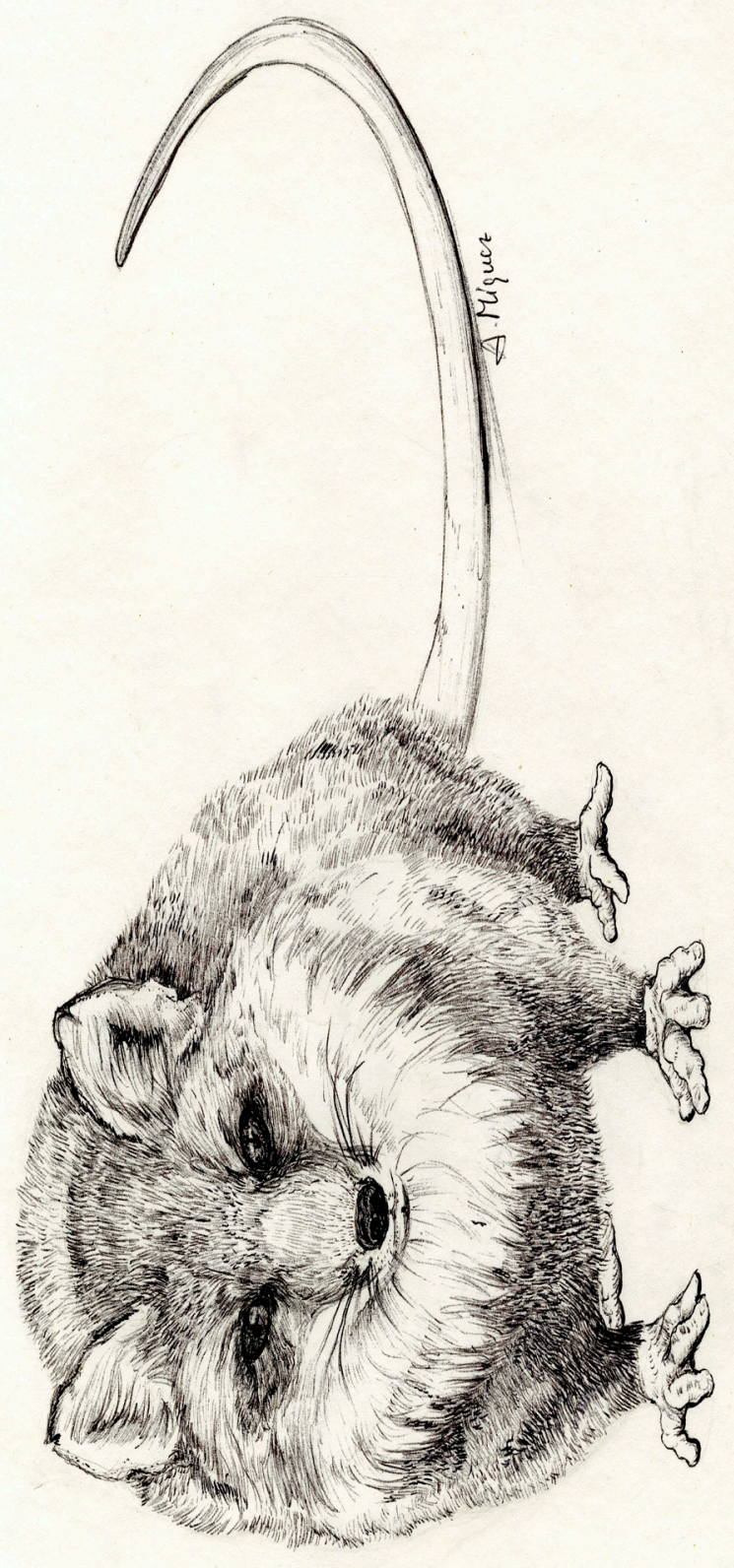


